\title{
KOLEKTIVNA IZKUŠNJA PREBEŽNIŠTVA IN DRUGIH OBLIK IZSELJEVANJA MLADIH PO DRUGI SVETOVNI VOJNI V PISNIH, USTNIH IN DRUGIH AVTO/BIOGRAFSKIH VIRIH
}

\author{
Mirjam MILHARČIČ HLADNIK
}

COBISS 1.02

\section{IZVLEČEK}

\section{Kolektivna izkušnja prebežništva in drugih oblik izseljevanja mladih po drugi svetovni vojni v pisnih, ustnih in drugih avto/biografskih virih}

Članek obravnava obdobje izseljevanja na Slovenskem od konca druge svetovne vojne do začetka šestdesetih let 20. stoletja, v katerem je poleg omejenih možnosti legalnega prehoda prevladovala oblika prebežništva oziroma ilegalnega prehajanja zahodne in severne meje. Izseljevanje in prebežništvo so povzročali številni dejavniki, ki so vsebinsko integralno najbolj natančno opisani v pisnih, ustnih in drugih avto/ biografskih pričevanjih akterjev dogajanja. Da bi osvetlil kompleksnost vzrokov za odhajanja med mladimi v obravnavanem obdobju, članek temelji na pregledu in primerjalni analizi osebnih izkušenj prebežništva in izseljevanja izbranih posameznikov. KLJUČNE BESEDE: izseljevanje, prebežništvo, avto/biografski viri, nadzor migracij, Jugoslavija/Slovenija

\section{ABSTRACT \\ Collective Experience of Defection and other Types of Youth Emigration after the Second World War in Written, Oral and other Auto/Biographical Sources}

The article deals with the period of emigration in the Slovenian territory from the end of WWII to the beginning of the 1960s. Beside the limited possibilities for legal crossing, the prevalent forms of emigration in this period were the illegal crossing of the western and northern borders or defection. The many reasons for emigration or escape are most thoroughly described in the auto/biographical testimonies of the agents of these practices. The article is based on an overview and comparative analysis of the personal experiences of emigration and escaping of the selected individuals. It aims to highlight the complexity of the reasons for the departure of young people during this period.

KEY WORDS: emigration, illegal migration, auto/biographical sources, migration control, Yugoslavia/Slovenia

Dr. sociologije, izr. prof., znanstvena svetnica, Inštitut za slovensko izseljenstvo in migracije ZRC SAZU, Novi trg 2, SI-1000 Ljubljana; hladnik@zrc-sazu-si — Prispevek je nastal v okviru raziskovalnih projektov »Nadzor nad migracijami na Slovenskem od Avstro-Ogrske do samostojne Slovenije« (J6-8250) in »Socialna, gospodarska in kulturna zgodovina slovenskega izseljenstva 1945-1991 « (J5-8246) ter raziskovalnega programa »Narodna in kulturna identiteta slovenskega izseljenstva v kontekstu raziskovanja migracij« (P5-0070). 


\section{UVOD}

V dveh desetletjih po drugi svetovni vojni so na slovenskem ozemlju potekale različne oblike intenzivnega izseljevanja. Ljudje so v dramatičnih okoliščinah zaprtih in strogo nadzorovanih meja odhajali kot begunci, izgnanci, ilegalni migranti ali prebežniki, v manjši meri tudi kot legalni migranti z urejenimi potnimi listi. Območja na slovenskem ozemlju so imela svoje specifike glede razmejitev, ki so določale življenjske okoliščine lokalnega prebivalstva in vplivale na njihove odločitve za odhod. $\mathrm{Na}$ severu se $v$ dveh desetletjih meje niso bistveno spremenile, na zahodu pa je razmejitvam sledila postavitev (začasne) meje, kar je imelo različne učinke na življenje ljudi in njihove odločitve. Spreminjali so se tudi ideološko, politično in zakonodajno urejanje prestopov meja ter stopnja strogosti mejnega nadzora in režim kaznovanja prebežnikov; ta je bil po letu 1951 omiljen (Lukšič Hacin 2019: 192). V prvih par letih po maju 1945 govorimo predvsem o množičnem begunstvu in izgnanstvu, ki je dobilo predznak politične emigracije (Švent 2007), od leta 1947 pa o prebežništvu, v katerem so se prepletali kompleksni razlogi za pobeg in skupna okoliščina, to je zaprtost meje (Mlekuž 2019: 164-166).

Nadzor nad gibanjem ljudi se je še okrepil po informbiroju leta 1948 in zaostrovanju hladne vojne. $V$ tem obdobju lahko pomembnejše mejnike urejanja in nadzorovanja prehajanja meje postavimo v leto 1951, ko je bil sprejet nov kazenski zakonik, in v leto 1962, ko je bil sprejet Zakon o amnestiji dotedanjih ilegalnih prebežnikov, če niso bili vojni zločinci. Na zahodni meji je pomemben mejnik leto 1954, ko so strogi mejni režim zrahljali Videmski sporazumi, čeprav je ostala meja, razen za domačine, skoraj nepropustna do začetka šestdesetih let (Čelik 2013). Prvi zvezni predpis o organiziranem izseljevanju iz Jugoslavije je izšel leta 1963. V tem obdobju so bila dovoljenja za prehod meje izdana na podlagi posebnih prošenj, nekatere druge možnosti, na primer združevanje družin, pa opisujem v nadaljevanju.

$\checkmark$ članku največjo pozornost posvečam prebežništvu, v manjši meri tudi legalnemu izseljevanju mladih do 25 . leta starosti. Mladi so bili prevladujoča starostna kategorija prebežništva v obdobju med letoma 1947 in 1962 (Božič 2013; Vidmar 2015). Osrednji namen članka je preseganje obravnavanja mladih kot žrtev nadzornih mehanizmov in težkih povojnih razmer. Izbrani primeri strategij upiranja, izogibanja in izkoriščanja institucionalnih in neinstitucionalnih nadzorov nad mobilnostjo želijo prikazati, kako so se mladi aktivno spopadali z omejitvami in s težavami, ki so jih vzpostavljali nadzori, prepovedi in omejitve. Bistvo omenjenih strategij je koncept avtonomnega delovanja. Avtonomno delovanje je treba razumeti kot sprejemanje racionalnih odločitev o mobilnosti v razmerah nadzorovalnih in omejevalnih mehanizmov lokalnih, državnih in meddržavnih struktur. Zato o avtonomnem delovanju lahko govorijo izključno migranti sami, zapleten proces tehtanja možnosti, priložnosti, omejitev in nevarnosti v kontekstu nadzorovanja in kaznovanja je namreč nemogoče raziskovati »od zunaj« oziroma zgolj s stališča struktur in mehanizmov. Metodološko lahko raznovrstne oblike avtonomnega delovanja mladih prebežnikov in 
izseljencev raziskujemo z narativnimi biografskimi metodami. S kvalitativno metodologijo in z upoštevanjem vseh etičnih omejitev, ki jih tak metodološki pristop zahteva, lahko avtonomno odločanje in delovanje proučujemo s pomočjo življenjskih zgodb, pričevanj, pripovedi, poglobljenih intervjujev in avto/biografskega gradiva.

$\checkmark$ članku je za primerjalno analizo kompleksnosti razlogov, motivov in načinov prebega oziroma odhoda izbranih sedem pričevalcev, ki so svoje izkušnje mladih prebežnikov oziroma izseljencev zabeležili v pisnih in ustnih spominih ter pričevanjih. Njihove subjektivne interpretacije okoliščin, v katerih so se odločili za odhod v tujino, so umeščene $v$ pregledni prikaz migracij povojnega obdobja ter $v$ oris avto/ biografskih virov, ki se v zadnjem desetletju množijo in so za podrobnejše razumevanje prebežništva in drugih oblik izseljevanja po drugi svetovni vojni dosegljivi nadaljnjim analizam.

\section{POVOJNE MIGRACIJE IN MLADI}

Po podatkih $v$ arhivih Sekretariata za notranje zadeve, ki jih je analiziral Marjan Drnovšek, je s slovenskega ozemlja med letoma 1947 in 1965 pobegnilo okrog 45.000 oseb, okrog 33.000 osebam pa so beg preprečili (Drnovšek 2010: 284). Koliko od teh so pri poskusu prebega ubili, ni znano. K temu številu moramo prišteti okoli 20.000 do 25.000 beguncev, ki so čez mejo zbežali takoj po osvoboditvi leta 1945 in pridobili status razseljenih oseb. Med njimi je bila skoraj celotna skupnost Kočevarjev, okrog 12.500 oseb, ki so morali ozemlje zapustiti po večstoletnem bivanju na Slovenskem. Izselitvi oziroma preselitvi je na Kočevskem sledilo vojno pustošenje vojskujočih strani in po koncu vojne množični izgon Kočevskih Nemcev (Tschinkel 2010). Ocena števila vseh izseljenih oziroma izgnanih Nemcev s slovenskega ozemlja je sicer veliko višja, okrog 25.000 (Nećak 2010). Obseg begunstva, izgnanstva in prebežništva dopolnjuje izselitev skoraj celotnega italijansko govorečega prebivalstva iz obalnih mest in zaledja, imenovanega optiranje ali eksodus, odvisno od interpretacije (Gombač 2005). Nevenka Troha ocenjuje, da se je med letoma 1945 in 1958 iz koprskega okraja izselilo 25.062 oseb: »Skupaj je območje, ki je bilo oktobra 1954 priključeno Sloveniji, tako zapustilo 27.810 oseb. Koliko je bilo med njimi Slovencev, ni znano, saj je nacionalna pripadnost navedena le na vlogah po oktobru 1953.« (Troha 2000: 261) Vsekakor so odhajali tudi prebivalci slovenskega porekla, zaradi odhoda prebivalstva pa se je popolnoma spremenila družbena in jezikovna struktura obalnih mest, ki so bila v naslednjih desetletjih ponovno naseljena (Kalc 2019).

Vasi so se pred vzpostavitvijo meje leta 1947 in po njej izpraznile tudi na severnem delu zahodne meje, na Tolminskem, Kambreškem in Goriškem. Ta meja je zarezala v skupni prostor in ni več dovoljevala tradicionalno uveljavljenih ekonomskih, socialnih in kulturnih stikov. Jernej Vidmar navaja podatke za goriški okraj, od koder je samo med letoma 1947 in 1951 zbežalo 2.694 ljudi, od tega 277 družin (Vidmar 2015: 126), za tolminski okraj pa ugotavlja: »Gotovo lahko trdimo, da so ljudje bežali 
skoraj iz vseh vasi takratnega okraja Tolmin. Pobegnili so z bovškega konca, iz breginjskega kota, s kobariškega območja, tolminskega konca, iz krajev okrog Mosta na Soči, z območja Planote, Šentviške gore in drugod. Največ jih je zbežalo iz vasi v Breginjskem kotu«. (Prav tam: 109) Maja Božič, ki je raziskala poročila Referata za meje RSNZ od 1945 do 1961, je na podlagi nepopolnih podatkov za prebege meje z Avstrijo ugotovila, da je bilo največ prebežnikov iz okrajev Murska Sobota, Maribor, Kranj, Ljubljana. Ugotovila je pomembno značilnost prebežništva, »da so Jugoslavijo zapuščali zelo mladi ljudje, stari med 18 in 25 let. Med njimi je bilo več moških kot žensk, kar nakazuje na beg pred vojaško obveznostjo v jugoslovanski vojski«. (Božič 2013: 32)

Razlogi množičnega odhajanja in bežanja so bili tako politični kot ekonomski, ideološki, verski in osebni, največkrat pa kompleksni in povezani s političnoekonomskimi razmerami povojnega obdobja. Bežali so delavci, kmetje, duhovniki, izobraženci, premožnejši in revnejši, predvsem pa mladi fantje pred vojaško obveznostjo in mlada dekleta pred pomanjkanjem življenjskih možnosti. Ljudje so se komunizma in nove oblasti bali iz ideoloških, političnih in verskih razlogov; mnogi so se bali ali so bili žrtve represije, ki je vladala že med vojno, po osvoboditvi pa se je nadaljevala; premožnejši so želeli zavarovati svojo lastnino, izobraženci svobodo, navaja Jernej Vidmar, ki razloge prebežništva takole strne:

Ljudi so poleg represije jugoslovanskega režima čez mejo pognale predvsem težke ekonomsko-socialne razmere v povojni Jugoslaviji, ki je le počasi okrevala od posledic vojne. [...] Ekonomsko-socialne stiske so bile tudi posledica politično-ideoloških ukrepov jugoslovanske oblasti v letih 1948-1953, zlasti na področju kmetijske politike, ki so prizadeli veliko število kmetov (agrarna reforma, obvezni odkupi, obvezna oddaja, kolektivizacija). (Vidmar 2015: 125)

Če strnemo približne ocene o izseljevanju, prebežništvu in begunstvu v dveh desetletjih po drugi svetovni vojni, lahko ugotovimo, da je bilo med njimi okrog 25.000 beguncev, 45.000 prebežnikov, ki jim je pobeg uspel, okoli 30.000 optantov in neugotovljeno število izseljencev s potnimi listi. Slovenijo je v dveh desetletjih zapustilo več kot 100.000 ljudi, poskus ilegalnega odhoda pa je bil preprečen 33.000 ljudem. To so zgolj približne ocene, s katerimi je podan oris obsežnosti fenomena, nikakor pa ne natančni podatki. Kot ugotavlja Marina Lukšič Hacin, je prav populacija prebežnikov »znotraj selitvenih študij v Sloveniji slabše raziskana, med drugim tudi zaradi pomanjkanja podatkov. Ocene o razsežnosti povojnega prebežništva se iz več razlogov, predvsem pa zaradi sistematične nedokumentiranosti, zelo razhajajo.« (Lukšič Hacin 2019: 193) Leta 1956 so slovenski partijski voditelji ugotavljali, »da se število pobegov čez mejo nenehno povečuje, da gre predvsem za ekonomske emigrante, da je med prebežniki kar 80 \% delavcev, med njimi tudi kvalificirani in visoko kvalificirani, in da je 73 \% emigrantov mlajših od 25 let« (Režek 2005: 949). Vsekakor so bili ilegalni prehodi meje pogosti, med prebežniki pa so prevladovali mladi. 


\section{AVTOBIOGRAFSKI VIRI ZA RAZUMEVANJE IZSELJEVANJA IN PREBEŽNIŠTVA}

V zadnjem desetletju je bilo zbranega veliko gradiva, v katerem raznovrstne izkušnje različnih oblik selitev in preselitev predstavljajo sami akterji tega povojnega dogajanja, nastale pa so tudi obsežne raziskave in analize avto/biografskega gradiva. Na portalu nacionalne televizije MMC so v arhivu oddaje Pričevalci na voljo številni posnetki izčrpnih pripovedi in pričevanj uspešnih prebežnikov, ki so se po različno dolgem bivanju v italijanskih in avstrijskih taboriščih kot ekonomski migranti izselili v Avstralijo ali pa preko avstrijskega ozemlja v druge države. Do danes je dostopnih deset posnetkov osemnajstih zgodb o vzrokih za pobeg in kompleksni izkušnji migracijskega procesa. ${ }^{1}$ Poleg pomembnih zbirk gradiva so nastale tudi poglobljene študije in analize migracij po drugi svetovni vojni. Doktorska disertacija Jerneja Vidmarja (2016) obsega natančen pregled nadzora in represije na meji med Jugoslavijo in Italijo med letoma 1947 in 1954 ter številna pričevanja iz arhivskih virov. Poleg teh je obdelanih še dvajset pričevanj, ki jih je avtor sam posnel in predstavil. Urška Strle (2009a) je v svojem prispevku o ilegalnemu izseljevanju iz Posočja v Italijo analizirala kompleksne politične, ekonomske, ideološke in intimne razloge za prebege, posnela in predstavila pa je tudi deset osebnih pričevanj. Avtorica je istega leta v knjigi Krila migracij objavila daljšo življenjsko zgodbo prebežnice iz Soške doline, ki se je iz italijanskega taborišča izselila v Kanado (Strle 2009). Marko Klavora je v disertaciji raziskal spomine prebivalcev Zgornjega Posočja na obdobje pred določitvijo meje leta 1947 in po njem, v katerih so omenjeni tudi prebegi, predvsem mladine (Klavora 2011).

Magistrsko delo Maje Božič (2013) prikazuje pojave prebežništva na severni meji med Jugoslavijo in Avstrijo med letoma 1945 in 1961. Poleg arhivskih virov je v nalogi predstavila tudi tri pričevanja, ki jih je sama posnela. Breda Čebulj Sajko (1999; 2000) je objavila poglobljene študije o avstralskih Slovencih, med katerimi so številni prebežniki. Analizirala je osemnajst življenjskih zgodb prebežnikov iz različnih delov Slovenije, ki so prebegnili v Avstrijo ali Italijo in se pozneje iz italijanskih taborišč izselili v Avstralijo. Številne življenjske zgodbe prebežnikov v Francijo pa so objavljene v posebni številki revije Korenine. ${ }^{2}$ Predstavljenih je trinajst pripovedi o osebnih izkušnjah izselitve mladih ljudi, med njimi je večina prebegnila. Irena Uršič je zbrala deset pričevanj o neuspelih prebegih po letu 1945 in zapornih kaznih, ki so sledile, ter jih objavila v knjigi Slovenija, duhovna domovina (Dežman, Kokalj Kočevar 2010: 247-298).

Poleg posnetkov življenjskih zgodb, ki so jih zbrali in objavili raziskovalci in raziskovalke, so na voljo tudi številna avtobiografska dela. Med objavljenimi avtobiografskimi deli prebežnikov velja omeniti dve avtorici, Josephine Janežič (1989) in Mirello

1 Vsa pričevanja so na voljo na spletni strani MMC: https://4d.rtvslo.si/arhiv/.

2 Mi, ki smo odšli: Pričevanja pariških Slovencev povojne generacije, Korenine, februar 2016: http://www.dlib.si/details/URN:NBN:SI:DOC-14RI3SF4/?euapi=1\&query=\%27keywo rds\%3dkorenine $+2016 \% 27 \&$ sortDir $=$ ASC\&sort $=$ date\&pageSize $=25$. 
Besednjak (2001), ter avtorja Valentina-Valija Oitzla (2010), ki so predstavljeni v nadaljevanju članka. V članku predstavljam tudi izkušnjo prebega Andreja Obleščaka, kot jo je opisal v daljšem avtobiografskem zapisu, ki ga hrani Tolminski muzej (Obleščak 2015), ter ustni pričevanji Marije in Jakoba Konc iz Babnega Polja, ki opisujeta drugačno izkušnjo, to je legalno izselitev na podlagi garantnih pisem oziroma združevanja družin. ${ }^{3}$ Velika večina prebežnikov je bila v času odločitve za pobeg stara med 18 in 25 let, zato je osrednja pozornost v prispevku namenjena prav tej populaciji.

\section{KOMPLEKSNOST VZROKOV IN RAZNOLIKOST NAČINOV ODHAJANJA SKOZI IZBRANA PRIČEVANJA}

Iz navedenih zbirk pričevanj mladih izseljencev in prebežnikov lahko razberemo najrazličnejše vzroke odhajanja. Med njimi je največkrat izražena mladostna želja videti in izkusiti svet onkraj zaprtih meja; ustvariti boljše življenje, kot so ga nudile takratne ekonomske razmere doma; zaslužiti višjo plačo in si privoščiti osnovne življenjske dobrine, ki so bile v prvih dveh desetletjih po vojni težko dosegljive; se izogniti služenju vojaškega roka, prisilnemu vstopanju v Komunistično partijo oziroma ideološkemu šikaniranju; in seveda ljubezen. Vzroki pa so bili tudi v represivnosti in krivičnosti režima, strahu in negotovosti ter navsezadnje v povsem intimnih presojah in predstavah o prihodnosti. Načini odhajanja so bili poleg prebega na zahodni ali severni meji še legalni obisk sorodnikov, npr. v Trstu, ali turistični izlet v Benetke in nato ilegalni prehod meje med Italijo in Francijo oziroma prekooceanska izselitev po določenem obdobju bivanja v italijanskih in avstrijskih taboriščih. Nekateri so se izselili s pomočjo garantnih pisem sorodnikov ali delodajalcev ter s potnimi listi, pridobljenimi na podlagi prošenj. Tako so se, na primer, med pričevalci v omenjeni reviji Korenine (2016) v dvoletnem obdobju med letoma 1963 in 1965 nekateri izselili s potnimi listi, večina, predvsem mladi fantje, pa je prebegnila v Italijo in nato ilegalno prečkala mejo med Italijo in Francijo. Med njimi je tudi pričevalec Franc Žagar.

Franc Žagar iz Bovca se je leta 1956 odločil za izselitev šele potem, ko se je pred služenjem vojaškega roka prišel poslovit od domačih in ugotovil, da je petnajst njegovih prijateljev in okrog trideset njegovih vrstnikov že pobegnilo v Italijo. »To me je začelo mikati: že od mladega sem poslušal od starega očeta, kako je bilo v Ameriki, in očeta, ki mi je na poti k maši pripovedoval o Franciji in Belgiji. (Prav tam: 20) Do takrat ni nikoli pomislil na odhod od doma, čeprav je bilo izseljevanje v njegovi družini, tako kot v številnih družinah na Slovenskem, pogosto. Franc Žagar na začetku pripovedi sam opozori na pomembnost družinske zgodovine migracij za razumevanje odločitev o izselitvi: 
Najprej moram povzeti zgodbo svojih prednikov, sicer se moje ne razume. Moj stari oče je bil dvakrat v Ameriki. Moj oče, rojen 1899 na Žagi pri Bovcu, je pri štirih letih ostal brez mame, pri dvanajstih je izgubil še očeta in ostalo je sedem sirot. Še kot mladoleten je pobiral cunje in steklenice pri nekem starčku v Borovljah na Koroškem. [...] Še mlad je, kot veliko drugih Primorcev, odšel v Francijo rudarit. Na severu, v Lensu, je kopal premog. Nekaj let zatem je doma na dopustu spoznal mojo mamo, oženil se je, dobil dva otroka in leta 1930 se je z družino odselil v Belgijo. (Prav tam: 17)

Franc Žagar se je leta 1937 rodil v Belgiji, leta 1941 pa se je družina vrnila na Bovško. Po vojni se je izučil za frizerja in delal v Kopru. Kot navaja v pričevanju, je rad gledal morje in mornarje in se je triletnega vojaškega roka v mornarici zelo veselil, a se je kljub temu odločil za izselitev. Izkoristil je možnost legalnega obiska sorodnikov v Trstu in se od tam odpravil proti francoski meji. Mejo je ilegalno prestopil na mejnem prehodu Ventimiglia-Menton, ki je tudi sicer najpogosteje omenjena točka prebega iz Italije v Francijo. Njegov osnovni motiv je izhajal iz odločitev prijateljev, vrstnikov in znancev iz domačega kraja, ki so $v$ tem obdobju množično zapuščali Bovec in okoliške vasi. Da se je ideja o odhodu - zaradi zaprte meje in zavračanja prošenj za potni list je bil to predvsem ilegalni prehod meje - med mladimi ljudmi širila kot nezaustavljiva potreba in možnost, je v svoji raziskavi ugotovila tudi Ksenija Batič.

Pričevalci so ji opisali, da sta bila odhajanje in prebežništvo med mladimi prava »moda« tistega časa: »Moda je bila. Zdaj, človek je odrasel v tisti vojni in bodočnosti dosti nismo videli doma in smo šli. [...] Mož je že prej tako, ko je kakšen krat kakšen tako pobegnil, je rekel: ^Ma kaj če bi tudi mi šli? Kaj če bi tudi mi?« (Batič 2003: 185) Že v prejšnjih obdobjih izseljevanja s slovenskega ozemlja zasledimo pomembnost skupinskega odločanja za izselitev, ko postane izseljevanje »moda« mladih in integralni del družinskih strategij celih območij, na primer goriških vasi, od koder so se množično izseljevale aleksandrinke (Škrlj 2009: 143). Franc Žagar poudari temeljno značilnost odločitev ljudi za selitev, ki ni zgolj osamljeno, individualno, enkratno dejanje, temveč je vpeto $v$ način življenja določene družine, skupnosti, kraja, regije. $O$ migracijah kot o »migrantstvu« (Mlekuž 2001: 27), torej socialno strukturiranem načinu življenja, ki vključuje raznolike oblike selitev ljudi v najrazličnejših političnih in ekonomskih okoliščinah, bi lahko govorili na območju celotnega slovenskega etničnega prostora vse od druge polovice 19. stoletja (Kalc, Milharčič Hladnik, Žitnik Serafin 2020). V tem smislu moramo prebežništvo po drugi svetovni vojni razumeti kot kontinuiran ustaljen odziv na okoliščine odsotnega oziroma zakasnelega razvoja in modernizacije (de Haas 2010) ter uporabe migrantskega kapitala v smislu podpornih mrež družine in skupnosti.

Povsem nasprotni razlog je botroval odločitvi Andreja Obleščaka iz Tolmina, vrstnika Franca Žagarja. Odraščala sta v enakih okoliščinah italijanskega fašističnega režima, druge svetovne vojne, povojnih razmejitvenih napetosti, poklicnega šolanja zunaj domačega kraja, revščine in pomanjkanja. Kot opisuje Andrej Obleščak v avtobiografiji, je bil svet blagostanja in boljših življenjskih možnosti na drugi strani meje, 
v Italiji, ves čas pred očmi: „Že 1948 so prvi italijanski turisti prihajali na Tolminsko z novimi Vespa in Lambretta motorji, ko si mi, reveži, še Rog bicikla nismo mogli nabaviti« (Obleščak 2015: 4). Med razlogi za množične prebege mladih je treba upoštevati bližino in vidnost italijanske družbe, ki je zaradi ameriške radodarne pomoči po drugi svetovni vojni premogla obilje materialnih dobrin, o katerih so ljudje na jugoslovanski strani zahodne meje lahko samo sanjali. Vidmar navaja:

Samo leta 1956 je z Bovškega pobegnilo 32 ljudi, predvsem mladih. Po vojni naj bi ljudje bežali predvsem zaradi slabo razvite industrije in posledično temu slabe možnosti zaposlitve. Od leta 1954 naj bi po poročanju ljudske milice na povečanje pobegov vplival celo podpis Videmskega sporazuma, ki naj bi omogočil večjo propagando z zahoda. (Vidmar 2016: 104)

Sanje mladih oziroma propagando, kot jih je označila policija, so spodbujale tudi represivne in avtokratske odločitve oblasti, ki so med mladimi povečevale občutek prikrajšanosti. Tako je bilo tudi v primeru, ki ga navaja Andrej Obleščak, ko so ga kljub drugačni obljubi vpoklicali v mornarico. Na vpoklic se je leta 1956 odzval, a se po rednem dopustu ni vrnil v puljsko kasarno. Razmislek in odločitve številnih svojih sovrstnikov je takole pojasnil:

Že od konca vojne so naši ljudje, posebno mladi, bežali iz Jugoslavije čez mejo v Avstrijo ali pa Italijo. S časom, do leta 1955, so Jugo oblasti podvojile stražo na meji, z ukazom, da streljajo na vsakogar, kdor skuša bežati čez mejo. [...] Sčasoma smo vsi mi, obmejni državljani, vedeli pogoje, katere mora prebežnik premostiti. Predvsem si moral oblastem v Italiji dokazati, da si političen, ne pa ekonomski begunec, ker če so te našli, da bežiš čez mejo samo iz ekonomskih razlogov, so te vrnili nazaj. Vsi begunci so izrabljali vidno nasprotje med komunistično Jugoslavijo in zahodno demokracijo in igrali to politiko na svoj mlin. Sklenil sem, da bom tudi jaz izbral to nasprotje v svoj prid. (Obleščak 2015: 12)

Njegova odločitev za izselitev je bila večstopenjska. Prvič je pomislil na beg pred »socialističnim nepotizmom in korupcijo režima«, ko so družino razlastili in jim odvzeli njive in polja. Pozneje je na odhod pomislil zaradi revščine, ki jo je bilo še težje prenašati zaradi izzivalnega blagostanja na italijanski strani meje, in skromne plače, s katero si ni mogel kaj dosti privoščiti. Na koncu je morda razmišljanje o odhodu postalo trdna odločitev prav zaradi zamere in prizadetosti, ki ju je čutil ob prelomljeni obljubi naborne komisije. Kot je razvidno iz nadaljevanja, so lahko prelomljene obljube in ponižujoče obnašanje oblasti ključne za kompleksno odločitev o izselitvi ali prebegu. Andrej Obleščak je po natančni preučitvi najugodnejše možnosti prebega s svojim dekletom mejo v Novi Gorici ilegalno prestopil februarja 1957. Kot politični prebežnik je živel v različnih italijanskih taboriščih in se leto pozneje kot ekonomski migrant izselil v Avstralijo. 
V avtobiografskih knjigah Pepčin boj Josephine Janezic in Roža med trni Mirelle Besednjak so opisani podobni motivi in izkušnje odhoda od doma. Obe avtorici sta na Primorskem prav tako odraščali pod italijansko fašistično oblastjo, med drugo svetovno vojno doživljali lakoto in strah, po njenem koncu pa huda, negotova leta. Obe mladi in željni boljšega življenja, ena iz Postojne, druga iz Mirna, sta se odločili za izselitev, Mirella Besednjak s prebegom, Josephine (Jožica) Janezic pa, tako kot Franc Žagar, z obiskom pri sorodnici v Trstu. Obe sta nekaj let preživeli v italijanskem begunskem taborišču in se izselili v Avstralijo oziroma Združene države Amerike.

Njuni razlogi, razmisleki in načini odhoda pa so se močno razlikovali. Razlog odhoda Mirelle Besednjak bi bilo lahko težko življenje po vojni v zasilnem prebivališču, saj je bila družinska hiša med vojno požgana. Težaško delo na udarniških »prostovoljnih « deloviščih in kmetiji, kjer je morala kot najstarejša hči ovdoveli materi pomagati pri skrbi za mlajše otroke, pa jo je izčrpavalo. A kot je zapisala, jo je tistega dne leta 1951, ko jo je prijateljica Ivanka nagovorila, da bi zbežali čez mejo in odpotovali v Ameriko, prešinila misel: »Kako bo materi sami z otroki, ona me potrebuje tukaj in tudi sama nimam razloga za odhod. Odločala sem se, ali bi šla ali ne, nato pa sem se opogumila. Pogledala sem Ivanko in ji rekla: >No, pa pojdiva.« (Besednjak 2001: 8) In sta brez prtljage odšli čez vrt in mejo, ki je bila v neposredni bližini. Kot navaja avtorica, je svojo odločitev kmalu obžalovala, »ampak takrat je bilo že prepozno« (prav tam: 10). Na njeno nenadno odločitev so vplivali vrstniški pritisk oziroma zgled in mladostni pogum, ne pa razmislek in dolgotrajno načrtovanje kot pri Andreju Obleščaku ali Josephine Janezic.

Vrstnica do zdaj omenjenih treh pričevalcev, Jožica Janezic iz Postojne, je imela številne razloge za odhod $v$ tujino in je svoj prebeg dolgo in natančno načrtovala. Po vojni je bila razočarana tako nad delom in šolanjem kot nad represivnim odnosom oblasti do vere in verujočih. Težko je prenašala novačenje za vstop v Zvezo komunistične mladine, življenje pa je postalo še težje, ko so zaprli očeta, ker je kot gozdar pomagal znancu pri prebegu meje, ta pa ga je prijavil policiji (Janezic 1989: 5). Odločitev o tem, da zapusti Jugoslavijo, je dozorela ob prvem obisku tete v Trstu, ko je spoznala mlada fanta, prebežnika, ki sta čakala na dokumente za odhod v Avstralijo, in se $v$ enega od njih zaljubila. Čeprav je bil prebeg Josephine Janezic načrtovan in je imela za svojo odločitev raznovrstne razloge, sta vendarle tudi pri njej odločilno vlogo odigrala zgled in pritisk vrstnikov. Tako kot odločitev Andreja Obleščaka je bila tudi njena premišljena, prebeg pa skrbno načrtovan. Najprej je hotela zavarovati svoje starše, predvsem očeta, ki so ga pravkar izpustili iz zapora, pred sankcijami zaradi hčerinega prebega. Morala je počakati, da dopolni osemnajst let in oblasti od staršev ne bi mogle zahtevati njene vrnitve. Odposlala je lažno tetino pismo, v katerem jo ta prosi, da pride k njej, ker je zbolela; oblasti so ji odobrile ponovni obisk. Predvsem pa je želela o svoji odločitvi obvestiti starše. Po vrnitvi v Postojno je ponovno zaprosila za dovoljenje za obisk, in ko ga je dobila, se je poslovila od očeta in matere: 
S solzami v očeh me je rotil, naj ne skrbim, ker spoštuje mojo željo, da zapustim deželo $v$ iskanju boljše prihodnosti nekje drugje. [...] Mama je tudi jokala od materinske skrbi in mi dala svoj blagoslov, me poškropila s sveto vodo, naredila križ na moje čelo in molila: »Bog, svojo hčer polagam v tvoje roke. Prosim, čuvaj in vodi jo, ker jo mi morda nikoli več ne bomo videli.« (Janezic 1989: 166-167)

Z vlakom se je odpeljala v Trst in se po par dneh pri sorodnikih, ki o njenem načrtu niso nič vedeli, marca 1954 prijavila v begunskem taborišču. V naslednjih dneh je uspešno prestala zaslišanja, pridobila status Displaced Person, torej 'razseljene osebe', se prijavila za izselitev v Avstralijo in dopolnila osemnajst let.

Čez severno mejo se je sam odpravil tudi Valentin-Vali Oitzl, ki svoje odločitve opisuje v avtobiografskem delu Polet $v$ svobodo. Prebegnil je leta 1950, ko je imel šestnajst let. Razlogi so bili kompleksen preplet etničnega porekla in medvojnih ter povojnih političnih razmer. Družina Oitzl je živela v majhni vasi Rute pri Gozd Martuljku, mama je imela gostilno, oče pa je bil lovski čuvaj. Med vojno so očeta in brata vpoklicali k partizanom, a so nemški vojaki brata ujeli, oče pa se je, da bi rešil sina, sam predal. Oba so izgnali v Lienz, od koder sta se vrnila po osvoboditvi, ko so očeta, tako kot veliko drugih t. i. »Volksdeutscherjev«, aretirali. Očeta so pozneje izpustili, mnoge, tudi nekatere sorodnike, pa so preko severne meje izgnali iz države ali pa so za vedno izginili. Valentin Oitzl je odraščal s smučanjem in skoki, saj je dobro »biti zaposlen s športom; tudi zato, ker nisi imel časa razmišljati, kaj se dogaja v deželi«. (Oitzl 2010: 28) Leta 1949 so očeta ponovno aretirali, premoženje zaplenili, družino pa izgnali na Kočevsko v izpraznjeno vas Morava. Kot navaja, so ga zaposlili v mizarski delavnici v Kočevju, sestro poslali kot "prostovoljko« v delovno brigado v Beograd, brat Gusti je hodil na gostinsko šolo v Ljubljani, oče pa je bil, tako kot številni drugi, obtožen »sodelovanja s kapitalisti ali pomoči ljudem na begu v Avstrijo. Pripisali so jim, kar jim je prišlo prav. A zelo so bili previdni, da so ožigosali samo ljudi, ki so jim lahko kaj vzeli«. (Prav tam: 39) Oče je bil obsojen na pet let prisilnega dela. Tega leta je dozorela Valijeva odločitev, da, ker je »imel vsega zadosti«, odide iz svoje dežele, kot pred njim nekateri njegovi sorodniki. Skrbno je načrtoval pobeg skozi kraje nad domačo vasjo Rute, ki jih je dobro poznal, a mu prvi prebeg v Avstrijo zaradi močnega sneženja ni uspel.

Vrnil se je v Kočevje in med prvomajskimi prazniki leta 1950 ponovno poskusil, tokrat uspešno: „Ne znam razložiti občutkov, ki so me v tistem hipu prevevali: Bal sem se, hkrati sem bil vzneseno vznemirjen in žalosten. Vse hkrati [...] Žalosten sem bil, a nekaj mi je govorilo, da imam pred seboj prihodnost. Življenje, ki sem ga živel, mi gotovo ni bilo namenjeno.« (Prav tam: 48) Pri Valentinu Oitzlu se povežejo nekateri do zdaj omenjeni elementi odločitev mladih za odhod: podporne mreže, ki so jih stkali izseljeni sorodniki in družinski člani; občutki krivice in omejenosti; upor proti izključenosti ter želja po drugačnem, boljšem življenju. Konec marca 1951 je kot najmlajši prebežnik iz Bremna izplul proti Kanadi svoji prihodnosti naproti. 
Legalno izseljevanje $v$ obravnavanem obdobju prikazujeta življenjski zgodbi Marije in Jakoba Konc iz Babnega Polja. Oba sta se v Francijo izselila na podlagi garantnega pisma, ki je takrat omogočal pridobitev dovoljenja za izselitev in potnega lista, ključne pa so bile podporne socialne mreže oziroma sorodstvene zveze in vezi. Tako kot je v svojem pričevanju poudaril Franc Žagar, je za razumevanje odločitev o odhodu treba razumeti družinske, sorodstvene in lokalne oblike migrantskih poti, ki so vse od srede 19. stoletja zaznamovale večino družinskih preživetvenih strategij na slovenskem ozemlju. Babno Polje, vas v odročnem delu jugozahodnega dela slovenskega ozemlja, je nazoren primer. Od druge polovice 19. stoletja so iz vasi potekale intenzivne migracije različnih oblik, trajne, krožne, povratne, sezonske in njihove kombinacije. Moški so odhajali v Združene države Amerike, in domov, kjer so ženske in drugi družinski člani vodili kmetije, pošiljali denar. Nekatere, ki so se vrnili, so nadomestili starejši sinovi ali pa so skupaj z njimi ponovno odšli. Moški so intenzivno odhajali tudi na sezonsko delo na Ogrsko oziroma Hrvaško, kjer so pozimi, ko jih doma niso potrebovali, delali v slavonskih gozdovih.

Ko so ZDA priseljencem zaprle vrata, so iz Babnega Polja in iz številnih drugih slovenskih krajev začeli množično odhajati v Francijo. $V$ obdobju med obema vojnama so se tako vzpostavile goste podporne socialne mreže, ki so, kot je razvidno iz nekaterih opisanih primerov, po letu 1945 močno vplivale na odločitve o izselitvi ali prebegu. Marija Konc iz Babnega Polja je v Francijo odšla leta 1957, pred njo pa so v Franciji delali njen oče, številni drugi sorodniki in vaščani. Med njimi je bil za njeno odločitev pomemben bratranec, ki je po vojni ponudil pomoč njeni ovdoveli materi in ji predlagal, da bi kateremu od otrok priskrbel dokumente za odhod in delo v Franciji. Čeprav so ji med vojno ubili moža in se je po njej težko preživljala, je ponudbo zavrnila. Marija je imela kot najstarejša hči težko življenje še zlasti zaradi materine hude poškodbe. Razlog za njeno odločitev za odhod pa ni bilo to, kar je v tem obdobju mlade spodbujalo k odhodu: ekonomske in politične razmere, ki so bile v Babnem Polju še zlasti dramatične zaradi hudega medvojnega nasilja, ki ga je utrpela vas; splošno pomanjkanje in še zlasti pomanjkanje v družini brez očeta; lažje in boljše življenje, za katerega je vedela, da obstaja v tujem svetu in konkretno v Franciji. Za odhod se je odločila iz povsem intimnega razloga, to je iz užaljenosti in prizadetosti, ki ju je povzročil materin predlog, naj se poroči in gre od hiše. To jo je tako globoko prizadelo, da je skrivaj pisala bratrancu in ga obvestila, da želi priti v Francijo:

To sem napisala od užaljenosti, zaradi ženitve. Mami nisem nič povedala in štirinajst dni je minilo, preden je pošta prišla tja in nazaj. [...] Pismonoša lepo pride, na pismu piše Janez Konc, v pismu pa vsa garantna pisma. Sem rekla: »Kdo je zdaj kriv mama? Zdaj ste vi krivi, nikar zdaj mene tožit. Če me ne bi hoteli poslati od hiše, ne bi imela te misli. Tako pa za ženit nisem. «Preveč sem bila zagrenjena, da bi samo ostala, delala in dala mir. Mama je potem jokala in prosila, pa vse zastonj. Jaz sem ji rekla, naj se oni sami komandirajo, in sem šla v Francijo. Janez je poslal garancijo, da on skrbi zame, medtem ko bom jaz dol kot tujka. Tisti papir je poslal, potem sem pa jaz morala v 
Ljubljano, najprej na slovenski, potem pa na francoski konzulat. Dobila sem hitro potrjeno in sem tisto jesen odšla v Francijo. Brat me je še do Ljubljane pospremil, pa sestrična, ki je tam živela se je prišla poslovit. Potem sem šla na vlak in prišla leta 1957 lepo v Pariz.

Neposredni povod Marijine odločitve je bil intimni občutek zamere, ki ga je povzročil materin predlog o ženitvi. Marija ga je razumela kot neupoštevanje njene nesebične skrbi za družino, ki je bila brez očeta, in nekaj časa, ko je bila v bolnici, tudi brez matere. Pa vendar lahko tudi njeno odločitev umestimo v migrantstvo Babnega Polja, torej v uveljavljene transnacionalne prostore, v katerih so se vaščani že stoletje premikali in živeli (Makarovič 1999).

Francija je bila v času med obema vojnama najpogostejši cilj slovenskih izseljencev v tujino (Kalc, Milharčič Hladnik, Žitnik Serafin 2020). Vzpostavili so trdne podporne mreže, te pa so po letu 1945 izkoristili prebežniki in izseljenci. Soprog Marije Konc, sicer doma iz Štajerske, je v Francijo legalno odpotoval na podlagi združitve družin, saj je tam živela njegova mama, ki se je v Francijo izselila leta 1936.

Oče je leta 1946 umrl. Jaz sem imel 14 let. Takoj po tistem, je mati začela papirje delati, da bi naju s sestro spravila v Francijo. Preden je oče umrl, nismo imeli stikov, po njegovi smrti pa se je pa nemudoma lotila delanja papirjev, da bi naju spravila v Francijo. Za sestro ji je uspelo dobiti papirje takoj, zame pa so rekli, da moram najprej vojsko odslužiti, ker je bilo takrat to obvezno, tako da sem tri leta preživel v mornarici. Po tistih treh letih sem prišel. Moja mama je takrat delala na jugoslovanski ambasadi in je relativno hitro dobila papirje in mi jih poslala. Sestra je šla že 1947 leta in je bila na ambasadi kot služkinja, mama pa kot čistilka. [...] Ko sem prišel v Francijo 1954, sta me čakala sekira in kolo, tako da sem prišel v nedeljo, v ponedeljek pa sem šel že delat v gozd.

Leta 2010 sta se Marija in Jakob Konc po 55 letih življenja in dela v Franciji preselila v Babno Polje. Zanimivo je, da so bili lahko v istem obdobju načini prehoda meje povsem različni. Nekateri so prebegnili, lahko tudi čez več kot eno mejo, v bolj ali manj dramatičnih in nevarnih okoliščinah. Nekatere so ujeli in so morali prestajati zaporne kazni, prisilno delo in težke razmere v zaporih; pogosto so zaprli, šikanirali in kaznovali tudi njihove sorodnike. Nekateri pa so, tako kot Marija in Jakob Konc, legalno s potnimi listi in povabilnimi pismi odšli na že vnaprej dogovorjena delovna mesta.

\section{ZAKLJUČEK}

Vzroke za odhajanje mladih v dveh desetletjih po drugi svetovni vojni lahko iščemo v ekonomsko-političnih in socialno-kulturnih okoliščinah takratnega vsakdanjega življenja. Za prebežniške motive in motive legalnega izseljevanja je značilen preplet 
lokalnih dejavnikov, za obmejna območja pa tudi različne razmere na obeh straneh meje. Lokalni kontekst namreč odločilno vpliva na konkretne aspiracije, možnosti in sposobnosti migriranja. Čeprav je treba migracije vedno razumeti v širšem socialnem, ekonomskem, kulturnem in političnem kontekstu, pa lahko o kompleksnosti vzrokov in motivov ter o načinih odhajanja mladih največ izvemo iz osebnih pričevanj akterjev povojnih migracij na Slovenskem. Mladih ne smemo videti (zgolj) kot žrtve povojnih okoliščin, pač pa kot aktivne akterje in avtonomne odločevalce. Razlogi, kot so jih opisali izbrani pričevalci, so bili zunanji, a hkrati osebni in intimni; odločitve hipne ali premišljene; odhodi pa dolgo načrtovani ali zgolj korak v neznano. Opisane so strategije avtonomnega delovanja in vsakodnevnega izumljanja načinov, kako doseči cilj - premikati se za dosego boljšega življenja. Gre za transnacionalne in translokalne podporne mreže ter dinamične, inventivne strategije akterjev mobilnosti, ki so jih narekovali državni sistemi nadzora mobilnosti ter politične, vojaške in ekonomske vzpostavitve meja in klasifikacij ljudi.

Kot dokazujejo avto/biografska dela in pričevanja mladih udeležencev izseljevanja in prebežništva, številni razlogi izhajajo tudi s kulturnih in psiholoških stališč kolektivne imaginacije mladih ljudi po drugi svetovni vojni. Najdemo jih v željah po osebnem razvoju, življenjskih izbirah, svobodi in blagostanju, sproščenosti in lagodnejšem vsakdanjem življenju na drugi strani zaprte meje, ki so jih doma zavirali opustošena dežela, prepočasno izboljševanje življenjskega standarda in represivni režim. Za razumevanje njihovih odločitev so ključni raven aspiracij in občutki relativne deprivacije. Težnje, želje in ambicije po boljšem življenju izvirajo iz predstave o tem, kakšno življenje si »zaslužijo« oziroma kakšnega življenja ne želijo živeti. Predstave o zaželenem življenju izvirajo iz dejanskih ekonomskih in političnih razlik med družbami v konkretnem zgodovinskem trenutku, prav tako pa tudi iz dolgoletnih izkušenj migracij v lokalnih skupnostih in družinah. Na slovenskem ozemlju so bile predstave o boljšem življenju v tujini globoko zakoreninjene že od konca 19. stoletja, tako da obravnavano obdobje v tem smislu ni nobena izjema. Nasprotno, gre za kontinuiteto izseljevanja iz slovenskega prostora, pri katerem so bili vedno najštevilčnejši prav mladi. Seveda pa so se okoliščine po letu 1945 radikalno razlikovale od tistih pred letom 1914, ko govorimo o svobodnih selitvah, ali poznejših, sicer veliko bolj restriktivnih, pa vendarle ne tako dramatičnih.

Načini in izpeljave odhodov in prebegov so bili povezani s podpornimi socialnimi mrežami, z drznostjo, s pogumom in srečo. Navedena pričevanja potrjujejo pomembnost socialnih podpornih mrež, saj številni pričevalci pripovedujejo o sorodnikih, prijateljih, znancih, ki so že bili v tujini in so jim lahko pomagali. Poleg tega pričevanja potrjujejo pomembnost »migrantstva«, to je obstoječih dolgoročnih migracijskih strategij družin in lokalnih okolij. Nekateri prebežniki in izseljenci so samo sledili vzorcem selitev, ki so jih pred njimi že ubrali drugi člani družine $v$ drugih časih in okoliščinah. Ključni element vseh pripovedi pa je želja po prostorski in socialni mobilnosti, vključenosti v svet potrošnje, blagostanja, obilja in napredka, kot so si ga mladi predstavljali in za katerega so bili prepričani, da jim pripada. Poleg upora 
proti izključenosti, omejevanju, diskriminaciji, krivicam, prisilam in prepovedim lahko v množičnem prebežništvu mladih po drugi svetovni vojni iz Slovenije opazimo predvsem stremljenje po identitetni preobrazbi ljudi, ki svoje pravo mesto iščejo v širnem svetu.

\section{LITERATURA}

Batič, Ksenija (2003). »Domovina je tu in domovina je tam«: Raziskava med primorskimi izseljenci o njihovi vrnitvi v Slovenijo. Dve domovini / Two Homelands 18, 181201.

Besednjak, Mirella (2001). Roža med trni: Moje življenje po koncu druge svetovne vojne. Miren: Oko.

Božič, Maja (2013). Prebežniki v Avstrijo 1945-1961. Magistrsko delo. Univerza v Ljubljani, Filozofska fakulteta, Oddelek za zgodovino.

Čebulj Sajko, Breda (1999). Med srečo in svobodo: Avstralski Slovenci o sebi. Ljubljana: Samozaložba.

Čebulj Sajko, Breda (2000). Razpotja izseljencev: Razdvojena identiteta avstralskih Slovencev. Ljubljana: Založba ZRC SAZU.

Čelik, Pavle (2013). Stražarji državne meje v Sloveniji (1918-2013). Ljubljana: Modrijan.

Haas, de Hein (2010). Migration and Development: A Theoretical Perspective. The International Migration Review 44/1, 227-264.

Dežman, Jože, Kokalj Kočevar, Monika (2010). Slovenija, duhovna domovina: Zgodbe političnih emigrantov. Ljubljana: Mladinska knjiga.

Drnovšek, Marjan (2010). Izseljevanje, »rakrana« slovenskega naroda: Od misijonarja Friderika Barage do migracijske politike države Slovenije. Ljubljana: Nova revija.

Gombač, Jure (2005). Esuli ali optanti?: Zgodovinski primer v luči sodobne teorije. Ljubljana: Založba ZRC, ZRC SAZU.

Janezic, Josephine (1989). Pepca's Struggle. New York: Vantage Press.

Kalc, Aleksej, Milharčič Hladnik, Mirjam, Žitnik Serafin, Janja (2020). Doba velikih migracij na Slovenskem. Ljubljana: Založba ZRC, ZRC SAZU.

Kalc, Aleksej (2019). The Other Side of the »Istrian Exodus«: Immigration and Social Restoration in Slovenian Coastal Towns in the 1950s. Dve domovini / Two Homelands 49, 145-162.

Klavora, Marko (2011). Zavezniška vojaška uprava (1945-1947) in spomini prebivalcev v Zgornjem Posočju. Doktorska disertacija. Koper: Univerza na Primorskem.

Lukšič Hacin, Marina (2019). Političnost migracij po drugi svetovni vojni: Od politike revanšizma do amnestije. Dve domovini / Two Homelands 5, 183-198.

Makarovič, Marija (ur.) (1999). Moje Babno Polje. Cerknica: Zveza kulturnih organizacij. Mlekuž, Jernej (2001). Prispevek za drugačno geografijo moči: Migracija, moč in identiteta v odnosu ena do druge. Dve domovini / Two Homelands 13, 25-50. 
Mlekuž, Jernej (2019). Nadzor nad nenadzorovanimi migracijami: Kako je slovensko časopisje pisalo o prebegih iz Jugoslavije v letih 1945-1965. Dve domovini / Two Homelands 50, 163-182.

Nećak, Dušan (2010). »Nemci« na Slovenskem ob koncu druge svetovne vojne - maščevanje ali pregon? (ur. Peter Štih, Bojan Balkovec). Migracije in slovenski prostor od antike do danes. Ljubljana: Zveza zgodovinskih društev Slovenije, 576-599.

Obleščak, Andrej (2015). Spomini Andreja Andrejcovega. Rokopisno gradivo. Arhiv Tolminskega muzeja.

Oitzl, Valentin-Vali (2010). Polet v svobodo: Beg, sanje in ljubi kruhek. Štanjel: Nassa Desella.

Tschinkel, John (2010). Zvonovi so umolknili. Ljubljana: Modrijan.

Troha, Nevenka (2000). Preselitve v Julijski krajini po drugi svetovni vojni. Prispevki za novejšo zgodovino 40/1, 255-268.

Režek, Mateja (2005). Nov koncept pravosodja in kazenske zakonodaje. Slovenska novejša zgodovina 1848-1992, 2. (ur. Jasna Fischer). Ljubljana: Mladinska knjiga, Inštitut za novejšo zgodovino, 947-950.

Strle, Urška (2009). »Bila je preprosto sreča, da sem prišla v Kanado«: O razlogih za selitve skozi Stankino življenjsko zgodbo. Krila migracij: Po meri življenjskih zgodb (ur. Mirjam Milharčič Hladnik, Jernej Mlekuž). Ljubljana: Založba ZRC, ZRC SAZU, 89-120.

Strle, Urška (2009a). »Pustili so vse in čez noč odšli.« Prispevek k ilegalnemu izseljevanju iz Posočja v Italijo po drugi svetovni vojni v luči ustnih pričevanj. Zgodovina za vse 1, 113-128.

Škrlj, Katja (2009). Komaj sem čakala, da zrastem in postanem aleksandrinka: Demitizacija aleksandrink. Krila migracij: Po meri življenjskih zgodb (ur. Mirjam Milharčič Hladnik, Jernej Mlekuž). Ljubljana: Založba ZRC, ZRC SAZU, 143-189.

Švent, Rozina (2007). Slovenski begunci v Avstriji 1945-1950. Ljubljana: Založba ZRC, ZRC SAZU.

Vidmar, Jernej (2015). Nadzor in represija na meji med Jugoslavijo (FLRJ) in Italijo v letih 1947-1954. Kronika 63, 119-136.

Vidmar, Jernej (2016). Nadzor in represija v prvem desetletju jugoslovanske oblasti na severnem Primorskem (1945-1955): Primer okrajev Gorica in Tolmin. Koper: Univerza na Primorskem.

\section{ČASOPISNI VIRI}

Korenine, 1916. 


\section{SUMMARY}

\section{COLLECTIVE EXPERIENCE OF DEFECTION AND OTHER TYPES OF YOUTH EMIGRATION AFTER THE SECOND WORLD WAR IN WRITTEN, ORAL AND OTHER AUTO/BIOGRAPHICAL SOURCES Mirjam MILHARČIČ HLADNIK}

In Yugoslavia and Slovenia, the period between 1947 and 1963 was characterized by closed borders, minimal opportunities for legal emigration and strict control of people's mobility. The estimated numbers show that of all those who left the country illegally in this period, around $75 \%$ were below the age of 25 . Young people wanted to leave the country for political, economic, social and cultural reasons, as well as a general resistance to political control, economic hardship, cultural deprivation and social exclusion. The article presents seven testimonies about defection and other types of youth emigration from Slovenia/Yugoslavia after the Second World War. It focuses on their agency and aims to avoid the discourse of their victimization or stigmatization. In their testimonies, they reveal diverse combinations of intimate, personal reasons for their decisions and the different ways of escaping or emigrating. Their common circumstances included not only political repression and lack of economic development but also the existing transnational support networks and the migrants' social capital. It is clear that the illegal emigration of young people should be understood as deeply embedded in already established "migrancy", and the survival strategies of families and local communities, and, since emigration is a crucial part of the history of the Slovenian ethnic territory, of the whole country. 